\title{
DOPS, a cidade de Rolândia (PR) \\ e a repressão aos imigrantes \\ de origem alemã (1942-1945)
}

\section{DOPS, Rolândia and the Persecution \\ of German Immigrants (1942-1945)}

\author{
ANgelo Priori \\ Programa de Pós-Graduação em História \\ Universidade Estadual de Maringá \\ Av. Colombo, 5.790, Bloco H-12, sala 16, Maringá, PR, 87.020-900, Brasil \\ angelopriori@uem.br
}

Verônica Karina Ipólito

Doutoranda, Universidade Estadual Paulista Júlio de Mesquisa, campus Assis

Laboratório de História Política e Movimentos Sociais

Universidade Estadual de Maringá

Av. Colombo, 5.790, Bloco H-12, sala 16, Maringá, PR, 87.020-900, Brasil

veronicaipolito@yahoo.com.br

Resumo $\mathrm{O}$ artigo analisa as ações realizadas pela Delegacia de Ordem Política e Social (DOPS) contra os imigrantes alemães, na cidade de Rolândia/PR, no período de 1942 a 1945. Durante a II Guerra Mundial e a adesão do Brasil aos países Aliados, os imigrantes dos países do Eixo foram vigiados e controlados pela polícia política do governo Vargas. A constante referência aos alemães acabou gerando a construção de mitos, como o da "conspiração alemã" e o da "Alemanha Antártica", que ajudaram a legitimar a "lógica da desconfiança" sobre esses imigrantes. A

Recebido: 6 de janeiro de 2015 | Aprovado: 24 de março de 2015

http://dx.doi.org/10.1590/0104-87752015000200010

Varia Historia, Belo Horizonte, vol. 31, n. 56, p. 547-580, mai/ago 2015 
construção de mitos políticos respaldou, no imaginário social, a atuação da polícia política, legitimando as suas ações de vigilância, controle e repressão.

Palavras-Chave polícia política, controle social, repressão, imigração alemã

Abstract The activities by the political police (DOPS) against German immigrants in Rolândia PR Brazil between 1942 and 1945 are discussed. The alliance of Brazil with the Allies during the II World War triggered the control and monitoring of immigrants from the Axis countries by the political police of the Vargas administration. The constant reference to Germans constructed a series of myths, such as 'the German Conspiracy' and 'Antarctic German' that legitimized the 'logics of suspicion' on the immigrants. The construction of political myths foregrounded in the social imaginary the actions of political police and legalized their control and persecution activities.

KEYWORDS political police, social control, repression, German immigration

\section{INTRODUÇÃO}

O Estado Novo (1937-1945) foi marcado pelo autoritarismo e pela repressão contra manifestações e ideias que não se coadunavam com o discurso oficial. Em nome da "segurança nacional", o regime estabeleceu todo um ordenamento jurídico-social para manter o controle dos indivíduos, estrangeiros e nacionais, e submetê-los à tutela do Estado. A intensificação das atividades das chamadas Delegacias de Ordem Política e Social (DOPS) ${ }^{1}$ consolidou o sistema de vigilância, controle e repressão necessário à sobrevivência do Estado Novo. Assim, os imaginários

1 Será utilizado sempre como referência a DOPS, já que o órgão, no Paraná, era conhecido como a Delegacia de Ordem Política e Social. Quando, no texto, houver referência como "o" DOPS, trata-se do órgão federal, que era um Departamento. 
sociais estiveram expostos aos "mitos" criados para inaugurar modelos exemplares de comportamentos.

Considerando que os mitos e as mitologias se desenvolvem no interior dos imaginários políticos, Raoul Girardet (1987) acredita que, apesar da renovação ocorrida nos anos de 1970, os estudos relacionados à história política ainda ignoravam o imaginário, pois negligenciavam os sonhos, as ilusões e fantasias. Nessa perspectiva, as novas abordagens voltadas para o âmbito político concentraram-se na construção de um discurso ordenado e tradicional. Para o autor de Mitos e mitologias políticas, houve a ausência de estudos voltados para a análise da "efervescência mitológica", que poderiam identificar as permanências políticas dos séculos XIX e XX, bem como a base de construções doutrinais na história europeia, como as conspirações, revoluções e a edificação da imagem de líderes heroicos. Essas associações eram estabelecidas aquém da macropolítica, compreendida aqui como o Estado e suas instituições.

Aos fenômenos institucionais e governamentais se impõe o mito, "constituindo ele próprio um sistema de crença coerente e completo", pelo fato de contemplar as aspirações integrantes no imaginário político, contemplando os pensamentos e interesses de determinada pessoa ou grupo (Girardet, 1987, p.11). Uma vez legitimado, o mito ou um conjunto de mitos ("constelações míticas") se desenvolvem livremente, podendo ser classificado à "direita" e à "esquerda", ao sabor das oportunidades de cada momento. Os papéis atribuídos a determinados mitos podem variar de acordo com o tempo e o espaço, segundo debates ideológicos e embates partidários (Girardet, 1987, p.12).

A ideia de conspiração, em uma análise mítica, não é acompanhada apenas de referências negativas. Sempre haverá a "sombra ameaçadora" e, em contraponto, a "sombra tutelar". Ambíguo e "polimorfo", o discurso mítico possui uma lógica de duas faces: a da "repetição" e a da "associação", as quais, combinadas com a imaginação coletiva podem renovar o discurso mítico, concedendo a ele múltiplas e variadas formas de combinação. A ligação de imagens com símbolos também aparece no discurso mítico. Dessa forma, "o tempo do Salvador, do chefe providencial aparecerá sempre associado a símbolos de purificação: o herói 
redentor é aquele que liberta”. Em contraste, a “conspiração maléfica sempre se encontrará colocada em referência a uma simbólica da mácula" (Girardet, 1987, p.17).

Em toda sua complexidade, o mito político pode ser visto como uma "narrativa legendária", que "exerce também uma função explicativa, fornecendo certo número de chaves para a compreensão do presente", bem como um "papel de mobilização", em função de seu caráter dinâmico. Para Girardet, a análise de mitos políticos possibilita aliar a história dos fatos sociais e a história das mentalidades coletivas, procurando fornecer um elemento novo de compreensão (Girardet, 1987, p.19-20).

No princípio da década de 1940, os cuidados em relação à imigração teuta fizeram com que a polícia política recorresse à formação de mitos, os quais, neste caso, assumem o papel de controle social. No período da Segunda Guerra Mundial, os alemães que viviam no Brasil eram vistos como a maior ameaça à segurança da nação, por sua forte ligação com a Alemanha e a disponibilidade de colaborar com o regime nazista. Todos os germânicos, sem exceção, eram identificados como suspeitos de espionagem ou de propaganda em favor do Terceiro Reich. Os locais de maior concentração de alemães se tornaram alvos de grande atenção do DOPS. Entre os ambientes de vigilância, inclui-se a cidade de Rolândia, no Norte do Paraná, a qual contou com forte influência da cultura alemã, principalmente no que se refere à preservação de seus hábitos, costumes, língua e valores. Considerando-se esse aspecto, não surpreende a intensa atuação do DOPS nessa cidade, fato que pode ser verificado pelo volume considerável de documentos referentes à Rolândia conservados no Departamento de Arquivo Público (DEAP), em Curitiba (PR), os quais foram utilizados nesta pesquisa.

$\mathrm{Na}$ historiografia sobre Rolândia, é comum encontrar depoimentos de pessoas que afirmam não ter conhecimento de qualquer atividade do DOPS naquela localidade, entre os anos de 1942 a 1945 (Pruser, 1957; Oberdiek, 1997; Schwengber, 2009; Soares, 2012). Por outro lado, os depoimentos de Geert Koch-Weser, de Max Hermann Maier e de Mathias Frings, inseridos no texto de Cláudia Schwengber (2012), confirmam as prisões de alguns alemães durante esse período, acusados de realizarem 
propaganda do regime nazista. Isto despertou ainda mais o interesse em preencher essa "lacuna" na história de Rolândia. No entanto, convém fazermos algumas observações: primeiro, o caráter secreto das investigações realizadas pela DOPS, principalmente em relação aos suspeitos de participar do Partido Nazista; segundo, a delegacia de Rolândia não era uma "DOPS", pois estas estavam centradas nas capitais estaduais (no caso, em Curitiba). Assim sendo, a delegacia municipal recolhia as informações e prendiam os suspeitos, que eram encaminhados para o órgão estadual, na capital do Estado. E, finalmente, com extinção da DOPS e a transferência de sua documentação para o Departamento de Arquivo Público do Paraná, ${ }^{2}$ possibilitou aos pesquisadores descobrir novos aspectos sobre a atuação desse órgão policial, bem como tecer as tramas sobre os investigados.

O objetivo deste artigo, portanto, está em apresentar alguns aspectos sobre a forma de atuação da polícia política em relação aos alemães residentes em Rolândia, no período da Segunda Guerra, procurando identificar os efeitos dessa ação nas vidas das pessoas, que, muitas vezes, nem mesmo compreendiam os motivos de estarem sendo vigiadas ou punidas. A construção de mitos, como o da "conspiração" e o da "Alemanha Antártica", ajudaram a legitimar a "lógica da desconfiança", por meio da qual todo o indivíduo que infringisse a ordem estabelecida seria considerado suspeito em potencial.

\section{Mitos POLÍTICOS E ORDEM SOCIAL}

Existem várias definições para o conceito de "mito", mas três delas se destacam. Primeiro, uma associação do mito às narrativas fabulosas e lendárias, geralmente de origem sagrada, e que procuram explicar determinadas situações, como o surgimento do universo (Eliade, 1972, p.7-10). Outra interpretação identifica o mito como uma camuflagem

2 Os documentos pertencentes a DOPS/PR foram transferidos ao Departamento de Arquivo Público do Estado do Paraná, por determinação do Decreto Estadual n. 577, de 11 de julho de 1991. 
do real. Neste sentido, a ilusão e a mistificação seriam produtos imaginários, impossíveis de terem um fundamento legítimo. Por fim, a análise de Georges Sorel (1990), mais flexível para as sociedades modernas. Segundo essa vertente, o mito possui caráter dinâmico, possibilitando a ação, como no caso do mito revolucionário.

Os mitos políticos que surgiram em fins dos anos de 1930 e início da década de 1940 não se encaixam em nenhuma dessas categorias. $\mathrm{Na}$ verdade, possuíam elementos das três conceitualizações apresentadas. Trata-se de uma "narrativa que elabora uma explicação para a realidade social, contém uma série de mistificações e propõe um programa de ação" (Motta, 1998, p.94). As construções mitológicas que vamos analisar neste artigo procuram moldar comportamentos considerados adequados para a manutenção da ordem social e para a legitimação da existência de um Estado autoritário. Também insistem em explicar as transformações vividas na modernidade como tendo sido provocadas por uma conspiração alemã disposta a fundar uma espécie de extensão de súditos nazistas em terras tupiniquins, com destaque para a cidade de Rolândia. A criação de mitos visa a neutralizar as supostas ações maléficas dos conspiradores ${ }^{3}$ e, simultaneamente, justificar a existência de um controle social mais rígido, representado por órgãos fiscalizadores, como o DOPS e suas extensões regionais.

Para melhor compreensão das ações da DOPS em relação aos alemães na cidade de Rolândia, é necessária uma contextualização do período abordado, ou seja, os anos de 1942 a 1945, durante o qual o Brasil define sua posição diante do conflito mundial, aderindo aos países aliados. Neste sentido, é indispensável ter em evidência aquilo que foi o Estado Novo, sua doutrina e forma de governo, principalmente naquilo que se refere à organização de sua polícia política, o DOPS, e a relação estabelecida com os estrangeiros residentes no país; a atuação do Partido Nazista no Brasil, de modo especial nas áreas de colonização alemã, os esforços para realizar um trabalho de propaganda e espionagem nazista;

3 A gênese dos mitos conspirativos remonta à Revolução Francesa, com uma série de reivindicações: como a conspiração dos aristocratas e da fome. (LEFEBVRE, 1979) 
e, ainda, um estudo sobre a cidade de Rolândia, seu histórico e sua situação no período da guerra.

O governo de Vargas, utilizando-se da estratégia da instabilidade política, procurou tirar vantagens de uma aparente "neutralidade". Sua inconstância para decidir a favor dos países aliados ou dos países do Eixo prolongou-se até, pelo menos, janeiro de 1942, quando anunciou o rompimento das relações diplomáticas, comerciais e financeiras com estes últimos. Em 31 de agosto, pelas pressões da opinião pública, declarou guerra à Alemanha (Cancelli, 1993, p.92).

No caso brasileiro, os intelectuais trabalharam para o convencimento da população sobre a necessidade de ter um Estado forte, cordial, jovem e patriota como meio de garantir a realização da democracia. Assim, tornaram-se comuns cenas de rememoração do passado e enaltecimento da história nacional. Utilizada dessa forma, a narrativa mítica edifica uma estrutura totalizante, capaz de legitimar práticas coercitivas e determinar regras de ordenamento social ou um sistema de hierarquização (Ansart, 1990, p.30). Nesse sentido, os serviços prestados pelo Departamento de Imprensa e Propaganda (DIP) tiveram grande importância, fazendo tanto a divulgação dos ideais do regime através de rádio, cinema, jornais e revistas, como também realizando forte censura sobre todos os meios de comunicação (Oliveira, 1982, p.75).

Até 1938, o governo brasileiro permitiu que os alemães mantivessem sua cultura, ou seja, a divulgação de seus hábitos, costumes, língua e valores. Livros sobre o nazismo, contendo hinos germânicos, relatos de viagem à "grande Alemanha" de Hitler, circulavam sem nenhuma restrição. No entanto, a partir desse ano, foi proibido falar, cantar ou ler em alemão. Qualquer material encontrado nesta língua era apreendido, não importando seu conteúdo. Certas profissões, como professor, jornalista, editor, escritor ou tipógrafo passaram a ser muito vigiadas e consideradas suspeitas (Carneiro, 1997, p.46). Nesse período, todas as restrições impostas aos estrangeiros se fizeram em função do nacionalismo. Após 1942, tais impedimentos continuaram sob alegação de prevenir a "segurança nacional". O depoimento de Geert Koch-Weiser é ilustrativo. 
Quanto aos problemas enfrentados pelos alemães em Rolândia durante a Segunda Guerra Mundial, podemos dizer que foram suportáveis. Quando da entrada do Brasil na guerra, suspeitavam que nós, como estrangeiros, podíamos ser inimigos. Era proibido falar alemão em público e devíamos entregar nossas armas. Não podíamos ter nenhum aparelho de rádio. Nossas propriedades agrícolas foram formalmente confiscadas, embora pudéssemos continuar a usufruir delas. Para cada viagem que fazíamos para fora de Rolândia, precisávamos de uma autorização escrita da polícia (salvo conduto) (Depoimento citado por Schwengber, 2012, p.274).

Para atender aos ideais do regime, foram criados os denominados "campos de internamento", verdadeiros "campos de concentração", destinados para prisioneiros do Eixo. Existiram nos Estados de Santa Catarina, São Paulo, Paraná, Rio de Janeiro, Minas Gerais, Rio Grande do Sul, Pernambuco e Pará, e funcionaram em todo o período no qual o Brasil participou da Segunda Guerra. Nos estados do sul e no Rio de Janeiro, a maioria dos presos nos campos eram alemães. Conforme análise de Priscila Perazzo, o perfil desses prisioneiros era "cidadãos alemães, civis, estabelecidos no Brasil, mas considerados, segundo a lógica policial, perigosos em potencial" (Perazzo, 1999, p.217).

São significativas as mudanças na legislação idealizadas por Vargas, bem como algumas realizações, nas quais fica evidente a intenção de reorganizar totalmente o Estado brasileiro. Entre as principais, destacam-se aquelas que se referem à "Ordem e Segurança Públicas" - como a dissolução dos partidos políticos, a criação e a organização do Tribunal de Segurança Nacional e da justiça eleitoral, de modo a multiplicar e aparelhar o judiciário no intuito de intensificar suas ações em relação ao controle social (Schwartzman, 1983, p.72).

Além disso, foram tomadas "medidas de segurança" visando a "prevenir e reprimir atos anti-sociais". Desse modo, os atos da imprensa em relação à "existência, a segurança e a integridade do Estado" eram considerados crime (Schwartzman, 1983, p.79). 
A atuação do DIP e do DOPS voltava-se para a pesquisa e análise de programas e organismos interessados em vigiar e "cuidar" da ordem pública, procurando inibir a prática de setores "extremistas" e politicamente contrários à ordem social vigente. $\mathrm{O}$ grupo-alvo a ser combatido no Estado Novo eram os denominados "alienígenas". Considerados pela polícia política como "antipatriotas", os estrangeiros - incluindo alemães, japoneses, italianos, dentre outros - eram vinculados a imagens de ervas daninhas, que, ao reproduzir sua cultura de origem, se transformaram em inimigos do Brasil. Portanto, a preocupação com a ordem social estava atrelada à eliminação de costumes, hábitos e cultura estrangeiras, legitimando a atuação de órgãos repressivos, necessários ao fortalecimento de uma nação sólida e independente.

Com o intuito de manter a "ordem social" nos moldes do discurso governista, construiu-se o mito da "conspiração" contra os estrangeirismos, a ponto de ser realizada a reformulação de toda a legislação sobre estrangeiros, como medida de segurança nacional. A nova legislação, criada em 1938, previa a rigorosa seleção de estrangeiros que vinham para o Brasil, manifestando preocupação em relação à origem do imigrante, a ponto de estipular "cotas imigratórias a várias nacionalidades", promover medidas que buscassem adaptação e a assimilação da cultura brasileira, bem como fomentar uma imigração voltada para a colonização (Schwartzman, 1983, p.109).

Em função da guerra, em abril de 1941, houve restrição da imigração, só podendo esta ocorrer mediante a autorização do Ministério da Justiça. Ficou proibido aos estrangeiros exercerem ou participarem de qualquer atividade de caráter político, visando a impedir que as colônias estrangeiras aplicassem no Brasil as doutrinas políticas de seus países de origem. Para certos crimes, ser estrangeiro tornou-se um agravante no processo de investigação. Algumas atividades foram proibidas aos estrangeiros, como: "dirigir estabelecimento de ensino; exercer profissões liberais; gerir empresas concessionárias de serviços públicos; obter concessão de minas ou quedas d'água, ou participar de sociedades para esse fim; possuir arma ou comandar navios nacionais", entre outras que pudessem ameaçar o interesse nacional (Schwartzman, 1983, p.110). 
A maioria dos estrangeiros que tentaram entrar no Brasil após 1939 estavam fugindo do conflito: os de origem judaica pelo antissemitismo alemão, outros por não concordarem com a doutrina nazista. Contudo, as suspeitas de que estavam formando em território nacional uma "quintacoluna" fez com que a polícia desconfiasse de todos os estrangeiros, de modo especial, daqueles vindos dos países do Eixo (Schwartzman, 1983, p.115). Assim, todos os imigrantes se tornaram alvos da DOPS. O que alimentava o "mito da conspiração", no caso dos alemães, era a suspeita de colaborarem com o regime do Terceiro Reich e do risco de separatismo que as colônias com população de origem alemã poderiam trazer, contaminando a unidade nacional brasileira.

No entanto, alguns estudiosos desconstruíram o mito da "Alemanha Antártica”, ou seja, a visão oficial compartilhada pela polícia política, que via nas comunidades germânicas fixadas no sul do Brasil interesses de anexar os estados do sul ao governo nazista (Gertz, 1987; Magalhães, 1998; Moraes, 1996; Athaides, 2012).

Segundo essa tendência, a percepção de que o Terceiro Reich teria planejado ocupar o Brasil utilizando a Ação Integralista Brasileira (AIB) como quinta-coluna é incompatível com o fato de que as lideranças nazistas "nunca partilharam da simpatia pela AIB e muito menos, mascararam a suástica atrás do sigma para anexar partes do Brasil, em especial as 'regiões coloniais' do Sul' (Athaides, 2009, p.3).

No período em que o Brasil participou da Segunda Guerra Mundial, o "mito da conspiração alemã" alimentou aquilo que em linguagem policial foi recorrentemente denominado de "perigo alemão". Portanto, não fica difícil compreender por que a cidade de Rolândia tornou-se alvo especial da DOPS, durante os anos de 1942 a 1945, pois foi colonizada por alemães, que representavam um número significativo entre os moradores do município.

\section{RolÂNdiA: UMA “CidAde AlEMÃ” NO NORTE do PARANá}

A colonização da região, na qual mais tarde viria a se formar a cidade de Rolândia, iniciou a partir de contratos firmados entre a empresa inglesa 
Companhia de Terras Norte do Paraná (CTNP) e a companhia de imigração alemã Sociedade para Estudos Econômicos no Além Mar - que era constituída por dez bancos, empresas de navegação, representantes de partidos políticos e industriais. Segundo Oberdiek (1997), esse projeto somente foi possível pelas condições históricas do momento: o Brasil, devedor dos bancos ingleses, estava precisando colonizar a região Norte do Paraná, após sucessivas tentativas de colonização fracassadas; a Inglaterra, apesar de não desistir de participar da "corrida imperialista", estava com dificuldades financeiras, devido, sobretudo, à Primeira Guerra e à crise de 1929; e, por fim, os interesses da Alemanha em promover a emigração para outros países fora da Europa, principalmente pela crise econômica que também a atingia.

$\mathrm{Na}$ visão de Oberdiek (1997), esse processo só pode ser compreendido se considerarmos os "reais" objetivos da CTNP, que consistiam, sobretudo, na exploração capitalista da terra, cujo foco era a venda de pequenas propriedades para estrangeiros; e na construção de ferrovias, que permitia o abastecimento de mercadorias para as colônias e o transporte de pessoas. A opção pelo imigrante alemão, e de modo especial, pelos judeus, não foi por acaso: eles possuíam o capital de que a CTNP necessitava, comprando as terras à vista, e ainda estavam sendo obrigados a emigrar da Alemanha, por uma questão de sobrevivência.

Os judeus que vieram para o Brasil eram, na maioria, pessoas abastadas, e este também é o caso daqueles que se instalaram em Rolândia. Segundo Oberdiek, custava muito sair da Alemanha, pois, além dos impostos pagos como "desertores do Reich", os imigrantes tinham que custear a viagem e também uma cota estabelecida pelo governo brasileiro de no mínimo 500 libras em aplicações no Brasil, no caso de judeus que quisessem ingressar no país (Circular secreta de 26 de setembro de 1938) (Oberdiek, 1997, p.90).

Desde 1930, a política implantada por Vargas em relação aos estrangeiros não era muito "acolhedora". Neste ano, foi totalmente proibida a entrada de estrangeiros no país. Em 1934, houve uma flexibilização, com a publicação dos Decretos 24.215 e 24.258, que permitiram que agricultores e técnicos, pessoas detentoras de imóveis no Brasil e estrangeiros 
casados com brasileiros que tivessem filhos brasileiros pudessem entrar no país. Havia também circulares secretas que impunham restrições, sobretudo à entrada de judeus, vistos com todos os estereótipos antissemitas que circulavam pela Europa (Oberdiek, 1997, p.117).

Contudo, as proibições não impediram que muitos judeus alemães entrassem no Brasil, mesmo que fosse com vistos de turista ou de forma ilegal. No caso de Rolândia, das 400 famílias de origem alemã que se instalaram na região, 80 eram judias. Em sua maioria eram intelectuais (médicos, advogados, dentistas etc.), e não agricultores, como determinava a legislação. No entanto, contrariando a lei, nos documentos de entrada no país, consta a profissão "agricultor" (Oberdiek, 1997, p.118).

Conforme análise de Oberdiek, a Companhia de Terras Norte do Paraná pretendia "ocupar o espaço e o tempo para sua reprodução ampliada, ou seja, obter maiores lucros com os menores investimentos possíveis" (1997, p.56). Assim, preferia vender terras a quem pudesse pagar à vista, antes mesmo de explorá-las. Nesse caso, os judeus alemães eram o público ideal, pois tinham muito capital para investir e estavam sendo obrigados a sair da Alemanha pela política antissemita desenvolvida por Hitler. A CTNP tinha também interesse (e necessidade) em continuar a expansão da ferrovia São Paulo/Paraná, que estava paralisada por falta de verbas. Como o governo alemão não permitia a saída de grandes capitais do país, principalmente de judeus, a forma encontrada foi a realização de uma "operação triangular". Os judeus compravam material ferroviário da empresa alemã Ferrostaal, que eram enviados ao Brasil, como forma de pagamento pelas terras da CTNP.

Com este projeto, realizaram-se em Rolândia cerca de 18 permutas, envolvendo 145 pessoas. Na realização desse empreendimento, destacam-se Erich Koch-Weser, ex-ministro alemão do Interior e da Justiça, Friedrich Wilhelm Lübke e Johannes Schauff, ex-deputados do Reichstag e ex-membros do partido católico Zetrum, dissolvido por Hitler -, os quais colaboraram para a vinda de refugiados do nazismo para Rolândia. No acervo particular de Johannes Schauff - funcionário da Sociedade para Estudos Econômicos Além Mar, em 1933 -, consta uma lista com 59 famílias de judeus alemães que se instalaram em Rolândia entre 1933 
e 1939 (Carneiro, 1996, p.137). Porém, com o início da Segunda Guerra, não foi mais possível realizar essa permuta, por se tratar de material estratégico para a guerra.

Apesar das dificuldades, ainda entraram no Brasil, no período de 1933 a 1939, cerca de 8.000 judeus refugiados, dos quais 291 se fixaram em Rolândia, número consideravelmente elevado, se comparado com a quantidade de imigrantes de outras etnias que passaram a residir no local durante este período (Oberdiek, 1997, p.91). No processo de transição para outro país, é natural que os imigrantes passem por uma fase de adaptação e reconhecimento da nova cultura. Entretanto, para evitar o esquecimento de suas tradições, é comum estabelecerem "referências partilhadas" (Felton, 2003, p.25), de forma a vivenciarem suas origens e perpetuarem seus hábitos e costumes. Tais práticas assustaram os órgãos de vigilância, os quais passaram a ver na imigração teuta uma ameaça aos princípios da brasilidade.

\section{As ATIVIDAdes do DOPS EM RolÂNDIA}

Os documentos da DOPS, produzidos pelos policiais, investigadores, delegados e também com a colaboração da sociedade civil, têm uma "verdade" a mostrar. Elaborados com uma riqueza de detalhes minuciosos, esses documentos têm grande capacidade de convencimento. Quem os elaborou queria mostrar, principalmente, aos cidadãos brasileiros, a existência de algum "perigo" ou "ameaça" para a sociedade. Isto servia tanto como justificativa para a ação policial (muitas vezes, abusiva e violenta), constituindo, no entanto, também um meio de controle das pessoas, as quais podiam ser identificadas como "perigosas". O objetivo, portanto, é compreender qual a "lógica" da DOPS, e que influenciou seu modo de agir diante daquilo que se convencionou denominar de "perigo alemão".

O forte nacionalismo do governo Vargas preocupava-se com a existência de colônias de estrangeiros, oriundas de um mesmo país, que podiam conservar sua cultura, tradições e língua, dificultando a assimilação com os brasileiros. De modo especial, os alemães apresentavam 
esse problema, sendo considerados os piores entre os estrangeiros. Costumavam reunir-se em clubes, associações e organizações alemãs como um meio de conservar suas "raízes" e manter o vínculo que os unia à Alemanha. Porém, os alemães de origem judaica, em geral, não participavam desses grupos. Não faziam questão de serem identificados como judeus ou descendentes de judeus, e muitos nem se consideravam alemães. Apresentavam uma característica internacional, tendo mais facilidade em assimilar-se ao país que lhes proporcionava condições para terem uma vida digna (Oberdiek, 1997, p.134). Em Rolândia, conseguiram estruturar uma nova comunidade, cujas relações se desenvolviam em meio ao sentimento de expatriação, da condição de refugiados e da necessidade de manterem a sua formação viva, independente do local em que residiam. Para estes alemães de origem judaica, o importante era "estar em casa no mundo através de um cosmopolitismo universal, no qual o pertencimento dos indivíduos não se deve a sangue e solo, ou a qualquer tipo de autoctonia fundamental ou fundamentalista. $\mathrm{O}$ indivíduo pertence em trânsito, está em casa em movimento e reside, de direito (institucionalizado por procedimentos justos), voluntariamente, numa sucessão de ambientes socioculturais em relação aos quais negocia" (Rapport, 2002, p.95). Segundo depoimento de Inge Rosenthal, "não houve uma comunidade judaica em Rolândia, mas sim uma comunidade intelectual composta por políticos, religiosos, professores universitários e profissionais liberais" (apud Justino, 2001, p.7).

No entanto, nos anos de 1942 a 1945, a atitude da polícia política brasileira em relação aos estrangeiros vindos dos países do eixo se radicalizou, e todos passaram a ser considerados "súditos do Eixo", ou seja, adeptos e/ou colaboradores do nazismo. Os judeus foram incluídos nesse grupo - fato totalmente contraditório, considerando-se as atitudes nazistas em relação a eles e os motivos que os levaram a imigrar para o Brasil -, sendo, da mesma forma, vigiados, investigados, processados e até presos.

Nos documentos da DOPS/PR, encontramos alguns exemplos de como esse órgão agia em relação aos judeus residentes em Rolândia. 
Consta, por várias vezes, a referência ao nome de Henrique Kaphan, judeu alemão tratado de forma especial pela polícia política.

Em relatório sobre a cidade de Rolândia, o delegado Arsênio G. Cordeiro diz que "vários alemães possuem duas residências nas suas propriedades, sendo que em uma delas só são recebidas as pessoas por eles autorizadas". Entre estes, destacam-se os Srs. Hans Kirchen (naturalizado) e Henrique Kaphan. Este último construiu a sua residência com operários alemães. Quanto ao Sr. Kaphan, realmente ele possuía duas residências em sua propriedade, mas uma delas foi construída com dinheiro de uma instituição judaica de auxílio aos judeus refugiados. Uma "casa de hóspedes", preparada para receber um grupo de jovens alemães, descendentes de judeus. Os pais desses jovens haviam comprado terras em Rolândia, no decorrer dos anos de 1930. Contudo, apenas um jovem desse grupo conseguiu chegar a sua propriedade no Brasil, Hans Rosenthal, graças à ajuda de um parente seu, que era amigo do cônsul brasileiro em Colônia (Carneiro, 1996, p.84).

Diante deste relatório, o delegado geral do DOPS encaminhou ofício à delegacia de polícia de Caviúna, atual Rolândia, solicitando as seguintes informações:

A) nome do assinante da caixa postal no 26 em Caviúna, B) nome do proprietário ou proprietários da Fazenda Jaú, na mesma localidade; C) quem é HANKE em Caviúna; se tem aparelho de rádio de qualquer espécie; quais as pessoas que costumam ir à sua casa a pretexto de ouvir rádio; que ligação tem ele com o proprietário ou empregados da fazenda Jaú; D) se existe na fazenda Jaú ou em Caviúna algum parente do Dr. ERNEST MORITZ MANASSE, ora nos Estados Unidos da América do Norte e quais os seus característicos de identidade, seus costumes, se lê e escreve em alemão etc. ${ }^{5}$

4 DEAP, Arquivo DOPS. Ofício n. 37, de 09/11/1942. Pasta 544 e, caixa 61.

5 DEAP, Arquivo DOPS. Ofício n. 210, de 18/08/1944. Pasta 0618 a, caixa 70. 
A resposta a este ofício foi enviada em 23 de outubro de 1944, pela delegacia de polícia de Caviúna (Rolândia), apontando Hermann Kaphan e Max Herman Maier como assinantes da caixa postal no 26 e proprietários da fazenda Jaú, os quais são classificados como de nacionalidade alemã e religião judaica. Sobre o Dr. Hanke, a delegacia informou que se trata de:

Eugênio Hanke, polonês, proprietário da fazenda Malta, onde reside, é sócio da Serraria Rolândia existente nesta cidade; é casado com polonesa; tem 3 filhos menores que se acham internos no Colégio Cristo Rei, em Jacarezinho; serviu no Exército Polonês ( $7^{\circ}$ R. C.) como aspirante; tem permanência legal no país e acha-se no Brasil desde maio de 1935; fala corretamente a língua alemã; tem aparelho de rádio, costumando ir à sua casa a pretexto de ouvir rádio, os seguintes alemães: Sr. Joaquim Markuald, Henrique Kaphan, Sr. Ricardo Loeb Caldenhof, os dois primeiros judeus; é íntimo amigo dos proprietários da fazenda Jaú; é representante da Cruz Vermelha Polonesa local, tendo sido indicado pelo Exmo. Interventor Federal ao Sr. Prefeito desta cidade para colaborar na campanha pró Cruz Vermelha Brasileira, há pouco encerrada, em cuja missão foi um dos que mais se destacou. ${ }^{6}$

Em relação ao Sr. Manasse, o relatório informa que não existia nenhum parente dele na região. Contudo, a DOPS de Curitiba insistia, em ofício n.1572, de 08/11/19447, para que fosse investigado melhor, e com urgência. Em 30 de novembro de 1944, a delegacia de Caviúna informava que Kaete Kaphan, alemã, esposa de Henrique Kaphan, era irmã de Ernst Moritz Manasse. ${ }^{8}$

Isso demonstra que o fato de ser judeu e/ou estar colaborando para a vinda de judeus refugiados ao Brasil não era visto com "bons olhos" pelo governo federal, o qual, apesar de estar integrando o grupo dos

\footnotetext{
6 DEAP, Arquivo DOPS. Ofício n. 61, de 23/10/1944. Pasta 0618 a, caixa70.

7 DEAP, Arquivo DOPS. Ofício n. 1572, de 08/11/1944. Pasta n. 0618 a, caiza70.

8 DEAP, Arquivo DOPS. Ofício n. 86, de 30/11/1944. Pasta n. 0618 a, caixa 70.
} 
Aliados, combatendo o grande inimigo dos judeus, não escondia seu forte nacionalismo e sentimentos antissemitas.

O interesse da DOPS em saber mais sobre os moradores e proprietários da fazenda Jaú pode ser entendido pela predominância de alemães nesta localidade. Era necessário, segundo a lógica da DOPS, saber cada passo desses indivíduos. Conforme apresenta o Ofício n. 210, ouvir rádio de qualquer espécie e reunir-se frequentemente com pessoas estrangeiras, fossem elas alemãs ou de outra nacionalidade, era considerado atitude suspeita.

Na realidade, o DOPS vinha se preocupando com os proprietários da fazenda Jaú desde o final dos anos de 1930. Existem anotações, datadas de 1939, sobre a chegada de grandes caixões, vindos do Uruguai:

Com um peso total de aproximadamente 3.000 quilos e, apesar da curiosidade despertada por um tal carregamento, numa localidade pequena como é, não foi possível a ninguém conhecer a natureza de carga, sendo que os caixões tinham vários destinatários, dos quais um era o alemão MAX HERMAN, conhecido por Dr. Max que reside a $9 \mathrm{~km}$ da cidade. ${ }^{9}$

Herman Hermann Maier era um dos proprietários da fazenda Jaú. Conforme constatou Oberdiek (1997, p.92), os judeus geralmente traziam uma bagagem bastante volumosa, com livros, utensílios valiosos, obras de arte e até pianos. Desse modo, é possível que esses caixões trouxessem esse tipo de material. O próprio Max Hermann Maier, em depoimento, confirma este caso.

Na nossa mudança, trouxemos caixões de livros. Quando estourou a Segunda Guerra Mundial, houve uma denúncia junto às autoridades militares. Afirmavam que nós alemães escondíamos armas e munições em nossas casas, porque nenhuma outra coisa poderia estar nessas caixas pesadas que chegavam da Alemanha. Foi então que a mais alta autoridade militar veio de Curitiba para vistoriar-nos. Era um homem culto e

9 DEAP, Arquivo DOPS. Ofício n. 37, de 09/11/1942. Pasta n. 544 e, caixa 61. 
letrado. Logo viu que na verdade as armas e munições não passavam de livros. Esta autoridade foi muito compreensiva, tanto para com os livros como para nosso destino de fugitivos (apud Schwengber, 2012, p.281).

Ainda sobre a vigilância aos judeus alemães, pode-se destacar a sistemática censura às correspondências encaminhadas ou oriundas do estrangeiro. É o caso da correspondência de Irma Koch-Weser, residente em Rolândia, que enviou uma carta para Elizabeth Frank, em Hollyridge, Estados Unidos. A carta foi apreendida ainda em Rolândia, pela "Censura Postal Brasileira", e a cópia da mesma foi encaminhada à delegacia de polícia. O então delegado de polícia e também prefeito da cidade, Ary Correia Lima, remete-a para o DOPS, destacando uma pequena passagem da carta, na qual se referia ao nome de uma pessoa chamada Ekhart, que "fazia parte do Estado Maior Alemão, na Rússia", e outra chamada Harald, a qual ainda estava desempenhando sua profissão, "devido a uma lesão no braço". ${ }^{10} \mathrm{O}$ delegado de Rolândia ainda destaca que:

As cópias e as informações acima são de caráter absolutamente confidencial, só poderão ser confiadas às autoridades superiores que do seu conhecimento necessitam no transcurso da guerra, não devendo em caso nenhum ser copiadas, usadas em processos judiciais ou divulgadas por qualquer meio, sem autorização expressa do Chefe de Censura. ${ }^{11}$

É notório que qualquer referência a assuntos políticos era motivo para despertar a atenção da polícia, tanto que, durante a guerra, as correspondências internacionais dos estrangeiros residentes no Brasil, eram censuradas e apreendidas. Significativa também é a preocupação com o caráter "secreto" do documento, ao qual somente podiam ter acesso algumas “autoridades superiores”. Essas, se necessário, a utilizam até mesmo como uma "prova" de envolvimento em atividades proibidas

10 DEAP, Arquivo DOPS. Documento de 30/12/1944. Pasta n. 0618 a, caixa70.

11 DEAP, Arquivo DOPS. Documento de 30/12/1944. Pasta n. 0618 a, caixa 70. 
a não nacionais. A remetente desta carta, Irma Koch-Weser, era irmã do diretor da Companhia de Estudos Econômicos de Além Mar, Erich Koch-Weser, alemão de origem judaica que veio no ano de 1934, para a cidade de Rolândia, juntamente com sua família, buscando, ali, um "refúgio".

Muitas vezes, os estrangeiros recorriam à ajuda das autoridades para resolver suas dificuldades. Encaminhavam seus pedidos, até mesmo ao Interventor Federal no Paraná, reivindicando interferência para amenizar os problemas que atingiam suas vidas, pelas restrições impostas pelas leis federais sobre estrangeiros. Em abril de 1941, a proibição do porte de armas aos estrangeiros não estabelecia exceções, fazendo com que muitos sofressem os efeitos dessa restrição. Os novos municípios, como Rolândia, não possuíam um número suficiente de policiais que dessem conta de proteger a população, seja urbana ou rural, de ataques criminosos (roubos, brigas etc.). Os estrangeiros, sobretudo aqueles que viviam na zona rural, eram alvos fáceis, visto que era do conhecimento a proibição de possuírem armas. Desse modo, a carta do Sr. Rudof Isay, residente em Rolândia, reivindica a intervenção sobre este assunto, para que fosse permitido a ele e aos outros lavradores daquela localidade possuírem armas para defesa pessoal. ${ }^{12}$

Na opinião do delegado do DOPS, não convinha atender ao pedido, visto que a lei federal não abria exceções sobre o assunto. Contudo, o Interventor Manoel Ribas autorizou a devolução das armas dos lavradores de Rolândia, as quais haviam sido recolhidas pela delegacia, "desde que os julguem insuspeitos de tendências subversivas".

Apesar da lei sobre estrangeiros não estabelecer exceções, estas poderiam ser aplicadas, e isso dependia da autoridade incumbida de tal decisão. No caso, o Sr. Manoel Ribas atendeu ao pedido do Sr. Isay, mesmo com a opinião contrária do delegado de polícia. Não sabemos, porém, que motivos o levaram a agir desse modo, nem tampouco, se essa determinação foi cumprida, mas, é importante não perdermos de vista o caráter repressivo do DOPS, que não queria abrir "exceções",

12 DEAP, Arquivo DOPS. Documento de 12/06/1942. Pasta n. 0618 a, caixa 70. 
pressupondo em todo estrangeiro uma "ameaça" para a ordem e segurança públicas, inclusive o judeu.

Geralmente, as leis que envolviam os estrangeiros não eram "suavizadas" pela polícia política. Qualquer atividade "ilegal” era investigada e punida. Tais práticas não se restringem ao período no qual o Brasil participa do conflito mundial. O controle sobre as atividades de estrangeiros era intenso, pois o governo de Vargas temia que pudessem estar propagando pelo país doutrinas políticas das nações de origem. As leis de nacionalização foram elaboradas para impedir este tipo de ação.

Os relatórios do delegado Arsênio Cordeiro, da Delegacia Regional de Londrina, mostram que em 1942 as diligências realizadas na região resultaram na prisão de mais de 60 pessoas, de várias nacionalidades, suspeitas de serem nazistas. ${ }^{13}$

A investida do Partido Nazista sobre as colônias alemãs no Brasil era forte, e, muitas vezes, os Consulados Alemães colaboravam para a propagação dos ideais nazistas, visando a obter algum tipo de ajuda dos súditos estabelecidos no Brasil. Em Rolândia, no ano de 1939, a polícia abriu inquérito para investigar as "responsabilidades" dos Srs. Josef Herions e Hans Zischeler, que estavam distribuindo "formulários para o registro de súditos alemães aptos ao serviço militar na guerra atual, conforme se verifica nos documentos anexos, o que constitui grave desrespeito ao artigo $4^{\circ}$ do decreto-lei n. 1.561 de 02/09/1939 que dispõe sobre as Regras Gerais de Neutralidade". ${ }^{14}$ Este decreto-lei dizia que era vedada a formação, em território brasileiro, de "corpos combatentes para servirem a qualquer dos beligerantes e bem assim a instalação de escritórios, agencias ou ofícios de alistamento, quer dos próprios nacionais dos beligerantes, quer de brasileiros ou de naturais de outros países". 15

A polícia apreendeu, com alguns acusados, formulários e panfletos nos quais havia apelos para que "os súditos alemães mostrassem a sua

13 DEAP, Arquivo DOPS. Ofício n. 188, de 27/08/1942. Pasta n. 544 e, caixa 61.

14 DEAP, Arquivo DOPS. Ofício n. 5194, de 30/10/1939. Pasta n.353, caixa 41.

15 DEAP, Arquivo DOPS. Ofício n. 5194, de 30/10/1939. Pasta n. 353, caixa 41. 
lealdade à pátria”. Após as averiguações, ficou comprovado que os investigados chegaram a distribuir este material na cidade de Rolândia, mas agiram pela influência do cônsul alemão de Curitiba, Dr. Walter Zimmermann, o qual admitiu a responsabilidade sobre o fato. ${ }^{16}$ Os dois investigados acima, tratavam-se do padre da igreja católica José Herions e do pastor da igreja luterana Hans Zischeler. Eles foram acusados, por um delator, de estar fazendo propaganda do regime nazista. Após a prisão, padre e pastor foram encaminhados a DOPS de Curitiba, onde o pastor, inclusive, sofreu inúmeros atos de tortura. Os dois religiosos só foram libertados, depois da ação do empregado do padre José Herions, Mathias Frings, que mobilizou o Arcebispo de Curitiba, Dom Ático Euzébio da Rocha, que por sua vez, intercedeu pelos acusados.

Logo, ambos foram postos em liberdade com a condição de não se afastarem da cidade [Curitiba]: tinham que ficar à disposição da polícia. Padre José ficou hospedado no convento dos franciscanos e o pastor foi acolhido na casa de um colega. Não demorou muito, a polícia reconheceu que ambos nada tinham feito de ilegal, e assim puderam voltar para suas casas (Depoimento de Mathias Frings; apud Schwengber, 2012, p.301-302).

Os casos dos dois religiosos são importantes para mostrar como a polícia política agia, tornando pessoas suspeitas pelos mínimos indícios ou por uma ingrata delação. O padre José Herions, por exemplo, não tinha nenhum vínculo com o nazismo. Pelo contrário, ele teve que fugir da Alemanha, em 1935, quando o regime hitlerista iniciou as perseguições aos religiosos e fiéis católicos (Schwengber, 2012, p.287; p.293).

A DOPS tomou cuidado especial com os membros do Partido Nazista no Paraná, procurando detalhar as informações sobre os seus membros e as atividades desenvolvidas no país. Para o DOPS, "as atividades político-sociais tornaram-se perigosas à segurança nacional". ${ }^{17}$

16 DEAP, Arquivo DOPS. Documento de 06/11/1939. Pasta n. 353, caixa 41.

17 DEAP, Arquivo DOPS. Documento de 23/06/1942. Pasta n. 0125, caixa 15. 
O documento elaborado pela DOPS de Curitiba, em junho de 1942, apresenta a vida de um alemão, nazista declarado, que colaborava para o partido:

Ricardo Kempper, 44 anos de idade, nascido na Alemanha, em 20/08/1898, casado com mulher alemã e filhos brasileiros, possui gabinete dentário e tem uma vida confortável. Residia em Curitiba, mudando-se repentinamente, sem motivo aparente, para a cidade de Londrina. Mantém contatos com pessoas suspeitas de serem nazistas, inclusive sua assistente, a qual é esposa de um oficial alemão e pessoa de confiança do Cônsul Alemão. ${ }^{18}$

Este documento mostra um pouco sobre o perfil do nazista elaborado pela DOPS: ter naturalidade alemã; casar-se com alemão; manter vínculos de amizade com outros nazistas, reunindo-se frequentemente; ter ligação próxima com o consulado alemão; ser parente ou ter amizade com algum oficial do exército alemão que esteja servindo à Alemanha ou que tenha servido na Primeira Guerra; receber, com frequência, visitas de alemães em sua residência e/ou local de trabalho, e ter uma vida muito confortável, sem desempenhar grandes esforços. Neste caso, ficam claras as atividades em prol do nazismo. Nota-se, entretanto, que muitas dessas características podem ser aplicadas a todos os alemães, inclusive aos judeus, o que não significa que todos sejam adeptos do nazismo.

A importância do Paraná para o Partido Nazista era grande. A ação do partido era disfarçada, sobretudo por meio de associações ou entidades assistenciais, bancos e empresas, agências de turismo, editoras, entre outras, pelas quais era possível realizar reuniões, manter o serviço de espionagem e propaganda sem despertar a atenção da polícia. Contudo, a polícia política brasileira, mesmo antes de 1942, já tinha agentes que se infiltravam em festas ou reuniões de estrangeiros, e mantinha forte vigilância sobre as empresas multinacionais (Perazzo, 1999, p.64).

18 DEAP, Arquivo DOPS. Documento de 23/06/1942. Pasta n.0125, caixa 15. 
O DOPS procurava identificar os "pontos de contato" entre a comunidade alemã no Brasil e o Reich, exercendo forte vigilância nas empresas e organizações alemãs, como bancos, agências de comunicação, associações políticas, recreativas e assistencialistas, indústrias, entre outras. Em 1942, por exemplo, o governo decretou a liquidação de muitas dessas empresas, como a Theodor Wille \& Co., empresa de exportação de café. $\mathrm{Na}$ cidade de Rolândia, os diretores das indústrias Scheffer foram alvos de vigilância do DOPS, no ano de $1943 .{ }^{19}$

Com a apreensão do arquivo do Partido Nazista paranaense, pode se verificar, por exemplo, por meio das declarações de Werner Hoffmann ${ }^{20}$, chefe do partido neste estado, que o Paraná era importante, pois representava a "divisa" entre o norte do país, onde predominava uma população luso-brasileira, e o sul, com forte presença do imigrante teuto. $\mathrm{O}$ que é interessante notar, é que também para o Partido Nazista, a região Sul do país era vista como um local "perigoso", que sofria constantes ataques por parte do Estado, seja na repressão ou nas iniciativas de nacionalização, e que, por isso, precisava receber atenção especial do partido, "assim como nos campos de batalha são reforçados os pontos que vão sofrer os ataques principais". ${ }^{21}$

Da mesma forma que grande parte da população alemã compartilhou dos ideais e sentimentos disseminados pelo Terceiro Reich, não se pode descartar a possibilidade de que os alemães presentes no Brasil também o fizessem. Tendo em vista a significativa colaboração concedida por eles, percebemos que realmente o partido conseguiu infiltrar-se, com certo sucesso, no país e no Paraná (Perazzo, 1999, p.19; Athaides, 2012).

Desde 1939, a Alemanha cuidou da instalação de redes de espionagem no Brasil, as quais tinham como principal objetivo obter informações sobre os Estados Unidos e Inglaterra, não ficando claro qualquer interesse em tomar o território, como o governo afirmava. O trabalho de espionagem realizado pelo Departamento do Exterior do Alto Comando das

19 DEAP, Arquivo DOPS. Documento de 28/06/1943. Pasta n. 0618 a, caixa 70.

20 DEAP, Arquivo DOPS. Relatório n. 9, de 11/06/1938. Pasta n. 125, caixa 15.

21 DEAP, Arquivo DOPS. Relatório n. 9, de 11/06/1938. Pasta n. 125, caixa 15. 
Forças Armadas Alemãs (Abwehr), na América do Sul, concentrou-se principalmente no Brasil, e as redes de outros países sempre mantiveram contato entre si, trocando informações (Hilton, 1983, p.16).

A tecnologia de espionagem desenvolvida pela Alemanha era admirável e avançada, para a época. Utilizavam tintas secretas para relatórios escritos que possuíam fórmulas químicas específicas - conhecidas como micropontos, ou seja, fotos que iam sendo reduzidas até ficarem do tamanho de um pingo da letra " $i$ ", podendo ser enviadas até mesmo por fora dos envelopes das cartas, sem que fossem descobertas - e a transmissão radiotelegráfica, realizada por meio do transceptor especial, o "Afu" - desenvolvido com a colaboração da Telefunken, pesando apenas $3 \mathrm{~kg}$, podia ser facilmente transportado numa mala pequena - tornaram-se a principal arma dos espiões (Hilton, 1983, p.29).

Mesmo com o preparo dos espiões e das orientações de Hamburgo para serem discretos e prudentes em suas ações, muitos deles cometeram erros graves, que resultaram em suas prisões. Em março de 1942, o aparato de espionagem alemã no Brasil já estava comprometido. Com a colaboração dos Estados Unidos e da Inglaterra, o Brasil, em pouco tempo, localizou e desestruturou a rede de espionagem alemã (Hilton, 1983, p.307).

O Partido Nazista teve forte influência também nos alemães residentes na cidade de Rolândia, no Paraná. Era importante para o partido contar com qualquer tipo de ajuda que seus súditos pudessem conseguir. Nessa cidade, houve grande propaganda do nazismo, principalmente através das escolas alemãs existentes na colônia. Contudo, em 1938, a campanha de nacionalização desenvolvida pelo governo determinou que nas escolas somente fosse permitida a comunicação em português. Por essa medida arbitrária, muitas escolas alemãs foram fechadas (Cancelli, 1993, p.136). Em Rolândia, o colono Elsembusch lamentava ter sido retirado o retrato do Führer da escola alemã, proibida a canção Horst Wessel e modificados os estatutos. O colono comentou ainda que o Reich somente tinha interesse em ajudar as escolas que se sujeitassem às suas conveniências. ${ }^{22}$

22 DEAP, Arquivo DOPS. Pasta 125, caixa 15. 
Contudo, houve muitos casos de alemães que se opuseram à doutrina nazista, de modo especial os que vieram refugiar-se no Brasil, como é o caso de judeus e católicos. Neste sentido, os arquivos do partido nazista mostram o caso de pessoas residentes em Rolândia que se retiraram da sociedade agrícola "por não concordar com o procedimento com relação aos nazistas". O presidente dessa sociedade era o Sr. Elsembusch, ao que tudo indica, um defensor do nazismo.

Para os nazistas, a Igreja Católica era uma inimiga declarada. Seu trabalho com os jovens no Brasil era considerado "danoso" para os ideais do partido. O padre católico José Herions, pároco em Rolândia desde 1935, conforme consta nos arquivos do Partido Nazista, se mantinha contrário aos adeptos de Hitler, e organizava grupos de jovens católicos, que incluíam filhos de alemães, doutrinando-os no catolicismo. ${ }^{23}$

No entanto, houve casos de padres católicos que colaboraram com o nazismo. Um relatório sobre a vida de monsenhor Scherer, elaborado pelo DOPS, apresenta um vocabulário raivoso, associando o sacerdote a um "elemento nocivo", "desclassificado" e "elemento dos mais perigosos". Residente em Rolândia e dirigente da comunidade católica daquela localidade, ${ }^{24}$ monsenhor Scherer, na ótica policial, abusando "de sua batina, serve como instrumento da Chefia Nazista da Alemanha e desempenha uma posição destacada como agente da Gestapo". A linguagem direta e agressiva utilizada pela polícia política sentencia o crime em vez de propor uma investigação. Os relatórios, compostos em sua maioria, por vocábulos coléricos alimentavam o ódio em vez de trazer esclarecimentos sobre a averiguação proposta.

Um investigador da DOPS “recuperou" os passos de monsenhor Scherer desde 1933, quando atuava na Europa, até a sua vinda para o Brasil, em 1936. Em seus relatórios, indicou que a fazenda do religioso, localizada em Rolândia, servia de refúgio para agentes da Gestapo, quando de passagem pelo Paraná. Outro documento fala da apreensão de armas,

23 DEAP, Arquivo DOPS. Pasta125, caixa 15.

24 DEAP, Arquivo DOPS. Documento de 07/04/1942. Pasta n.0618 a, caixa 70. 
rádio e fotografias com motivos nazistas, na propriedade rural do monsenhor Scherer. ${ }^{25}$

$\mathrm{Na}$ redação dos documentos evidencia-se a ideologia incutida na ótica do relator do DOPS, que vê o "perigo alemão" como uma ameaça à segurança pública e aos cidadãos brasileiros. Aponta-o como indivíduo sem valor, por estar compartilhando de uma ideologia - o nazismo considerada "degradante". Essa forma de visão faz parte da ideologia elaborada pelo governo autoritário de Vargas, o qual não admitia qualquer "ameaça" ao seu poder, ou mesmo a existência de adeptos de outra ideologia (Oliveira, 1982, p.53).

Os documentos pesquisados possibilitam também uma visão de como era realizado o trabalho do Serviço de Registro de Estrangeiros (SRE). A centralização destes serviços no Departamento de Imigração, ligado às polícias do Distrito Federal e dos estados, já ocorria desde maio de 1938, período em que passa a agir sistematicamente. Com o início da participação do Brasil na guerra, este serviço sofreu uma reformulação, sendo incumbido de desempenhar as funções de registro, controle e fiscalização de estrangeiros. O SRE era responsável pelo envio da carteira Modelo 19, um importante meio de controle dos estrangeiros, tornando-se indispensável para viverem no país, pois era obrigatório retirá-la e atualizá-la regularmente (Schwartzman, 1983, p.115). Esta carteira era de fundamental importância para os estrangeiros, visto que:

Era praticamente impossível viver no Brasil sem esta, podendo ser preso a qualquer momento. Nela contém foto da pessoa, impressão digital, assinatura, idade, nacionalidade, nome dos pais, cor da pele, dois números de registro, dez páginas de regulamentos da polícia de estrangeiros escritas em letras minúsculas, nome do navio no qual a pessoa chegou, número do visto de entrada, cor dos olhos e outras coisas igualmente indispensáveis (Carneiro, 1996, p.20).

25 DEAP, Arquivo DOPS. Relatório n. 173, de 22/08/1942. Pasta 544 e, caixa 61. 
A revalidação constante da carteira fazia com que o SRE estivesse sempre com informações atualizadas sobre os estrangeiros. $\mathrm{O}$ atraso implicava em cobrança de multas para o indivíduo, sendo de praxe o SRE solicitar informações às delegacias sobre determinadas pessoas, para regularização da presença no país, como é o caso de Margarethe Popper ${ }^{26}$ e Otto Glueck, ${ }^{27}$ alemães residentes em Rolândia. Cabia ao SRE cuidar da legalização da presença de estrangeiros no Brasil, o que poderia ser negado - como ocorreu muitas vezes, de modo especial com os judeus - caso a DOPS julgasse a pessoa como "perigosa" à segurança nacional.

O controle social exercido pela DOPS, na época da guerra, ainda que privilegiasse os eixistas, se estendia a toda a sociedade. O delegado regional de Londrina determinou, em 1942, que, em todos os municípios e distritos da região, os bares e as casas de diversão fechassem à meianoite, proibindo, ainda, qualquer tipo de reunião em casas de família.

Fez parte deste controle a utilização de "fichas" especiais para hotéis e pensões, as quais permitiam controlar a circulação de estrangeiros que passavam pelas cidades. A delegacia regional de Londrina comunicou a DOPS, em outubro de 1942, sobre a confecção dessas fichas, que seriam enviadas a toda regional, ${ }^{28}$ da qual Rolândia fazia parte.

Nos anos de 1942 a 1945, restringiu-se a liberdade de locomoção, para a qual era necessária a retirada de "salvo-condutos". Este tipo de autorização permitia saber detalhes sobre os motivos de viagens ou de mudanças de endereços residências ou comerciais, e, se a DOPS julgasse necessário, não concedia esta autorização.

Alemães que precisavam viajar constantemente a negócios tiveram sérias dificuldades, pois isso era motivo de suspeita por parte da DOPS, principalmente para aqueles que já haviam sofrido inquérito policial. $\mathrm{O}$ caso do padre Herions, em Rolândia, é um bom exemplo: em 1938, o pároco foi investigado pela DOPS por suspeita de colaboração nazista,

26 DEAP, Arquivo DOPS. Ofício n. 1859, de 28/12/1944. Pasta n. 0618 a, caixa 70.

27 DEAP, Arquivo DOPS. Ofício n. 176, de 31/01/1945. Pasta n. 0618 a, caixa 70.

28 DEAP, Arquivo DOPS. Ofício n.765, de 31/10/1942. Pasta n. 544 e, caixa 61. 
tornando-se um suspeito em potencial, mesmo que, após aquele episódio, não tenha causado nenhum outro tipo de problema na cidade, lhe foi negada permissão para viajar a Jacarezinho, em 1943. ${ }^{29}$

As prisões, muitas vezes, se baseavam em denúncias. O papel da população, naquilo que se refere à sua colaboração com a polícia, foi incentivado e considerado de fundamental importância. Para a polícia, não interessava a veracidade das denúncias, mas a participação popular nas atividades de vigilância. Muitas vezes, as delações eram falsas e infundadas, levando à prisão de inocentes, visto que a simples suspeita levava o sujeito a ser detido antes mesmo de ser comprovada sua culpa. Era comum ocorrerem denúncias com o objetivo de vinganças pessoais ou por razões financeiras (Cancelli, 1993, p.140).

A denúncia feita em dezembro de 1943 por Estebão de Figueiredo, ${ }^{30}$ residente em Rolândia, mostra, por um lado, o protecionismo das empresas alemãs aos funcionários de origem germânica, os quais ocupavam os melhores cargos e recebiam os melhores salários. Por outro lado, a acusação revela as intenções vingativas por parte do denunciante, o qual, levado por questões financeiras, principalmente depois que deixou de trabalhar na empresa, recorreu às autoridades policiais para que investigassem tal empresa.

As denúncias serviam também como forma de "autorizar" as atitudes abusivas da polícia, que não media esforços no combate ao chamado quinta-colunismo. Tais atitudes alimentavam ideias conspiratórias em relação aos imigrantes de origem alemã, seja dos populares ou do próprio órgão policial. As diligências realizadas nas casas de estrangeiros suspeitos eram muito comuns. O delegado regional de Londrina, no ano de 1942, entrou em várias casas de alemães, baseando-se em "suspeitas" de atividades em favor do Reich.

Nessas diligências, era apreendido todo tipo de material localizado com os estrangeiros, como rádios, armas, fotos, documentos, bandeiras do Reich etc. Dependendo do tipo de objeto encontrado, o sujeito era

29 DEAP, Arquivo DOPS. Ofício n. 1645, de 24/06/1943. Pasta n. 0618 a, caixa 70.

30 DEAP, Arquivo DOPS. Documento de 31/12/1943. Pasta 0618 a, caixa 70. 
imediatamente detido. Em agosto de 1942, o delegado da Regional de Londrina deteve o suíço Gaspar Ernest, por possuir uma "moderníssima arma de guerra", sendo esta utilizada como justificativa para a prisão. Esta arma era idêntica àquela que consta no livro Hitler guerreia o Brasil há dez anos, editado pelo chefe do DOPS, o qual era utilizado como uma espécie de "guia" para identificar adeptos do nazismo. ${ }^{31}$ Uma pena que os documentos não dão maiores informações sobre esta "moderníssima arma”, citando-a, de forma genérica.

O mito da conspiração alemã foi alimentado pela matriz nacionalista. $\mathrm{O}$ viés patriótico que motivou o antissemitismo e mesmo manifestações de repúdio aos imigrantes alemães no Brasil se inspirou no romantismo alemão do século XIX e na concepção corporativista. A soma dessas vertentes resultou em um ideário defensor da nação como uma unidade orgânica, superior, e que não admitia qualquer conflito social. De tonalidades conservadoras, tal nacionalismo destacava a manutenção da tranquilidade, a defesa das tradições e a necessidade de centralização, combatendo as forças centrífugas que visavam a minar a unidade e corromper a ordem. A atuação dos imigrantes alemães era condenada por cultivarem os seus hábitos e manterem vivos os costumes germânicos, a ponto de praticarem sua língua em solo brasileiro. Tais práticas, no entanto, eram interpretadas pela polícia política como tentativas de romper a noção de "corpo" nacional. As suspeitas de que os alemães estariam corrompendo a ordem social, e mesmo colaborando para fundar uma "quinta-coluna" ou uma "Alemanha Antártica" no sul do país, ofereceram subsídios para que o setor policial e parte da sociedade que colaborava, geralmente de forma deturpada, com as investigações, formulassem ideias conspiratórias em relação a estes imigrantes. Pode-se afirmar que tais construções mitológicas foram significativas para a manutenção de círculos conservadores e conformistas, os quais elegiam inimigos como forma de adquirir maior controle sobre a sociedade.

31 DEAP, Arquivo DOPS. Ofício n. 264, de 25/09/1942. Pasta n. 544 e, caixa 61. 


\section{CONSIDERAÇõES FINAIS}

A análise das fontes permite concluir, que, conforme determinação nacional, também a DOPS paranaense agiu com a devida rigidez, ou seja, sua ação sobre os estrangeiros seguiu as normas nacionais. As atividades da DOPS em Rolândia também não se diferenciaram em relação à generalização, pois todo estrangeiro foi considerado "suspeito", não havendo exceções, mesmo para os alemães de origem judaica, os quais vieram buscar um refúgio na região.

O regime de colaboração com os alemães, incentivado durante o governo Vargas, sofreu mudanças consideráveis a partir de 1937, momento de mudanças políticas substanciais que inauguraram o Estado Novo. O recrudescimento com a segurança nacional e o rompimento de relações diplomáticas com os países do eixo, sobretudo com a Alemanha, em 1942, contribuíram para a disseminação, em larga escala, de "mitos políticos" como padrões de comportamento. Dentre esses, destacamos o "mito da conspiração alemã" e o "mito da Alemanha Antártica".

Constituindo-se como um "sistema de crença coerente e completo", os papéis atribuídos a determinados mitos podem variar de acordo com o tempo e o espaço, segundo debates ideológicos e embates partidários (Girardet, 1987, p.12). Alguns dados da realidade ajudam a compreender por que tais mitos se viabilizaram. O discurso estadonovista defendia a construção de uma nação forte, cordial e patriota, justificando a necessidade de um governo capaz de eliminar os estrangeirismos e valorizar a cultura nacional. No bojo dessa narrativa mítica, surge a necessidade de controle social, a ponto de atribuir poderes a instâncias incumbidas de fiscalizar a ordem, tais como o DOPS e suas instâncias regionais.

$\mathrm{Na}$ ânsia de estabelecer um projeto nacional e combater os elementos estrangeiros, sobretudo os eixistas, implantou-se um conjunto de regras que restringiram, cada vez mais, a entrada de alemães no Brasil, bem como a tentativa de eliminar traços culturais e linguísticos das colônias teutas no país. A vinculação dos alemães com o nazismo, intensamente combatido no contexto da Segunda Guerra Mundial, permitiu a alguns setores de segurança nacional - como a polícia política - a cooptação 
dos alemães, muitas vezes foragidos de guerra, a representantes do Terceiro Reich, que tinham planos de construir, em terras tupiniquins, uma espécie de quinta-colunismo ou "Alemanha Antártica". A associação, sem exceções, do elemento teuto aos projetos nazistas possibilitou a criação do "mito da conspiração alemã", legitimando a ideia da "lógica da desconfiança”, na qual qualquer indivíduo (nesse caso, alemães) poderia ser um suspeito em potencial.

O volume de pastas arquivadas no Departamento de Arquivo Público do Paraná (DEAP) referentes à cidade de Rolândia é bastante significativo. O que mais chama atenção, no entanto, é o conteúdo desse material, por meio do qual se constata o cuidado da Delegacia em registrar todo tipo de acontecimento que envolvia estrangeiros.

Percebemos que o DOPS utilizava intensa campanha na propagação da ideia do "perigo alemão", visto que tudo que faziam podia ser interpretado como um tipo de colaboração para com a Alemanha e o Reich. Os alemães residentes na cidade de Rolândia foram forçados a mudar certos hábitos corriqueiros, como ouvir rádio, frequentar bares, ou mesmo manter vínculos de amizade com outros alemães ou brasileiros. Foram muitas as dificuldades para conseguir notícias sobre parentes que ficaram na Alemanha, visto que suas correspondências eram censuradas pelo governo brasileiro, e, dependendo do conteúdo, podiam resultar até mesmo na abertura de inquérito policial. Participar de associações de ajuda aos refugiados do nazismo também era motivo de suspeita, podendo ser considerado como agravante no processo de investigação, pois demonstrava que a pessoa mantinha ainda uma forte ligação com a Alemanha.

No entanto, não restam dúvidas de que o partido nazista agiu também em Rolândia, e, muitas vezes, suas atividades eram disfarçadas por meio de associações e entidades assistenciais. Conforme consta nos arquivos do próprio partido apreendidos pela DOPS, a Sociedade Agrícola, por exemplo, demonstrava claramente sua posição favorável ao nazismo, fazendo inclusive propaganda do regime. Isto fez com que as pessoas que não concordavam com esta posição, pedissem o cancelamento como sócias. Ao que tudo indica, o partido não estabeleceu redes de 
espionagem naquela cidade - como ocorreu em São Paulo e Rio de Janeiro, por exemplo -, mas procurou, de todas as formas possíveis, manter a identidade com a Alemanha, por meio da preservação da cultura e da propaganda do regime.

Podemos afirmar que a DOPS, tendo o respaldo legal para agir, não precisava "justificar" ou "medir" suas ações sobre os alemães. Assim, era comum o abuso de poder que se efetivou em invasões de domicílio e prisões baseadas somente em denúncias populares, muitas vezes infundadas. Era comum a polícia política atribuir certas características aos alemães como sendo próprias de espiões ou colaboradores do nazismo, como, por exemplo, reunir-se com outras pessoas "a pretexto" de ouvir rádio.

Porém, os alemães geralmente conservam muito sua cultura em qualquer local que venham a residir, e isto não foi diferente em Rolândia. Até 1938, não havia nenhuma lei que os proibisse falar em alemão ou manter seus costumes de origem. Como já foi dito, o governo brasileiro tinha admiração pelo povo alemão, visto como uma "raça forte", opinião que se modifica um pouco após 1938 com as leis de nacionalização.

Desse modo, as atividades desenvolvidas pela DOPS na cidade de Rolândia indicam, por um lado, que o Estado Novo, preocupado em legitimar-se no poder, obteve sucesso ao elaborar a "lógica" de um "perigo alemão" ou "mito da conspiração alemã”, daí a mobilização dos agentes e da sociedade civil para combater este "mal". Por outro lado, o autoritarismo deste governo, refletido nas práticas de sua polícia política, levou-a a agir, muitas vezes, de forma abusiva. Atribuir, porém, aos alemães a intenção de estabelecer uma extensão da Alemanha nazista em algumas regiões do Brasil, acreditando terem eles conspirado secretamente a favor destes objetivos, é partilhar do terreno do mito, no sentido de pura fabulação, o que não é conveniente à pesquisa histórica.

\section{Agradecimentos}

Pesquisa financiada pelo CNPq e pela Fundação Araucária. Verônica Karina Ipólito é doutoranda com bolsa CAPES. 


\section{REFERÊNCIAS BIBLIOGRÁFICAS}

ANSART, Pierre. Ideologias, conflitos e poder. Rio de Janeiro: Zahar, 1990. ATHAIDES, Rafael. A Historiografia e as relações nazi-integralistas. In: Anais do XXV Simpósio Nacional de História: História e Ética. Anpuh, CD-ROM, 2009.

ATHAIDES, Rafael. O Partido Nazista no Paraná (1933-1942). Maringá: Eduem, 2012.

CANCELLI, Elizabeth. O Mundo da Violência: a polícia da era Vargas. Brasília: Editora da Universidade de Brasília, 1993.

CARNEIRO, Maria Luiza Tucci. Brasil, um refúgio nos trópicos. São Paulo: Estação Liberdade, 1996.

CARNEIRO, Maria Luiza Tucci. Livros Proibidos, Ideias Malditas. O DEOPS e as minorias silenciadas. São Paulo: Estação Liberdade, 1997.

ELIADE, Mircea. Mito e realidade. São Paulo: Perspectiva, 1972.

FELTON, Steve. Etnicidade. Lisboa: Instituto Piaget, 2003.

GERTZ, René. O fascismo no sul do Brasil: germanismo, nazismo, integralismo. Porto Alegre: Mercado Aberto, 1987.

GIRARDET, Raoul. Mitos e mitologias políticas. São Paulo: Cia. das Letras, 1987.

HILTON, Stanley. A Guerra Secreta de Hitler no Brasil. Rio de Janeiro: Nova Fronteira, 1983.

JUSTINO, Adriano. Moser + Israel + Max ou o antídoto ao veneno nazista. Gazeta do Povo (Curitiba), n. 26.227, p.7, ago. 2001.

LEFEBVRE, Georges. O grande medo de 1789. Rio de Janeiro: Campus, 1979.

MAGALHÃES, Marionilde Brepohl de. Pangermanismo e nazismo: a trajetória alemã rumo ao Brasil. Campinas: Edunicamp/Fapesp, 1998.

MORAES, Luís Edmundo de Souza. Ein Volk, Ein Reich, Ein Führer. A Seção Brasileira do Partido Nazista e a Questão Nacional. Rio de Janeiro, 1996. Dissertação (Mestrado em Antropologia) - Museu Nacional/Universidade Federal do Rio de Janeiro. Rio de Janeiro, 1996.

MOTTA, Rodrigo Patto Sá. O mito da conspiração judaico-comunista. Revista de História, n. 138, p.93-105, 1998. 
OBERDIEK, Herman Iark. Fugindo da morte: imigração de judeus alemães para Rolândia-PR, na década de 1930. Londrina: Eduel, 1997.

OLIVEIRA, Lúcia Lippi (Org.). Estado Novo: Ideologia e Poder. Rio de Janeiro: Zahar, 1982.

PERAZZO, Priscila Ferreira O perigo alemão e a repressão policial no Estado Novo. São Paulo: Arquivo do Estado, 1999.

PRÜSER, Friedrich. O "Roland" e Rolândia. Notas que acompanham a inauguração de uma estátua do Roland na cidade brasileira de Rolândia. Bremen: R. Bergman, 1957.

RAPPORT, Nigel. Em louvor do cosmopolita irônico: Nacionalismo, o "judeu errante" e a cidade pós-nacional. Revista de Antropologia, vol. 45, n. 1, p.89-130, 2002.

SCHWARTZMAN, Simon. (Org.) Estado Novo, um autorretrato (arquivo Gustavo Capanema). Brasília: Editora Universidade de Brasília, 1983. SCHWENGBER, Cláudia Francisca Portellinha. Aspectos históricos de Rolândia. Rolândia: Wgraf, 2009.

SCHWENGBER, Cláudia Francisca Portellinha. Pioneiros alemães em Rolândia. In: VITECK, Harto (Org.). Imigração alemã no Paraná: 180 anos. Marechal Cândido Rondon: Germânica, 2012. p.257-308.

SOARES, Marco Antonio Neves. Da Alemanha aos Trópicos. Identidades Judaicas na Terra Vermelha (1933-2003). Londrina: Eduel, 2012. SOREL, Georges. Réflexions sur la Violence. Paris: Seuil, 1990. 